CII)

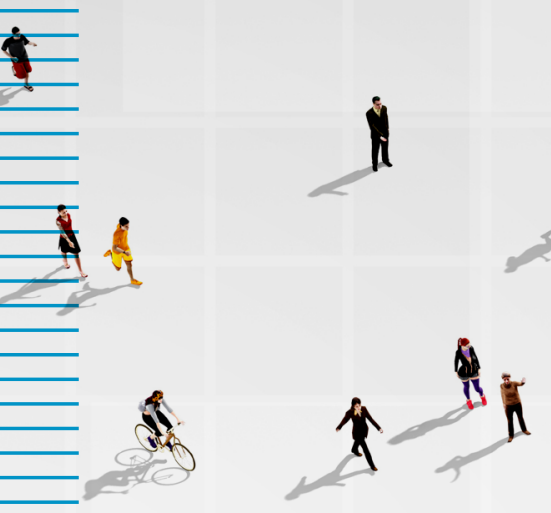

$$
\text { ( }
$$

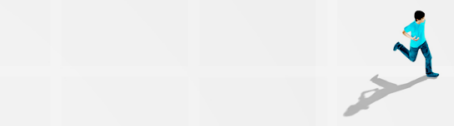

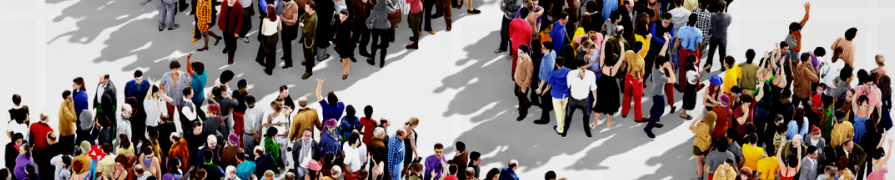

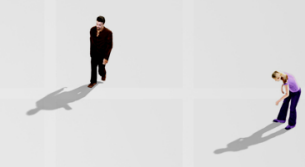

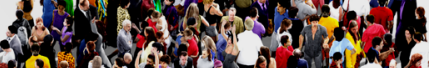

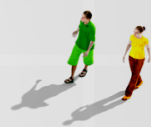

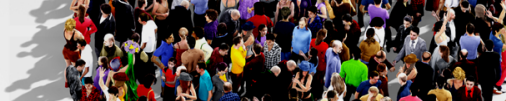

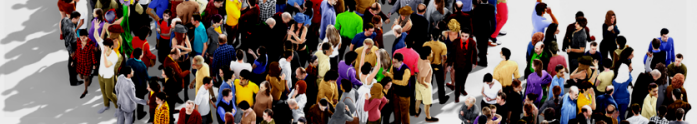

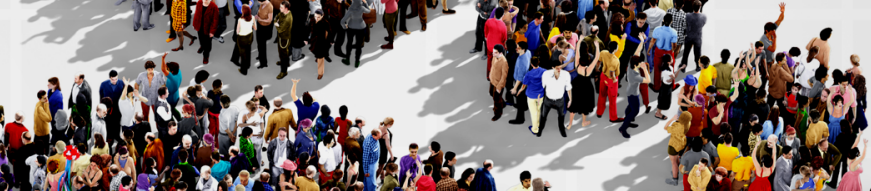

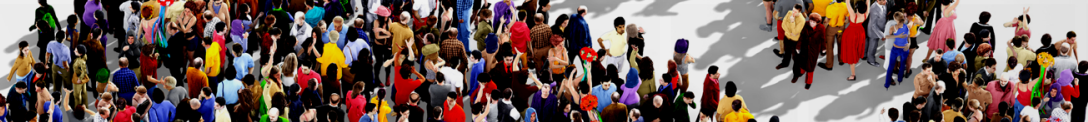

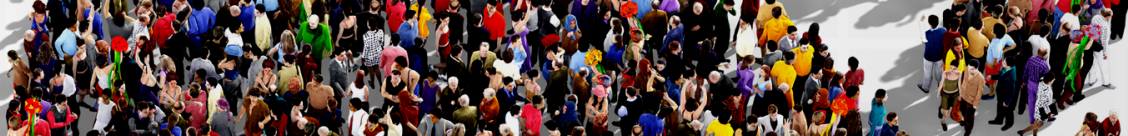

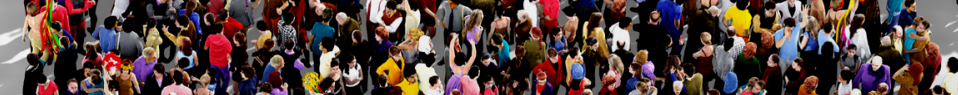

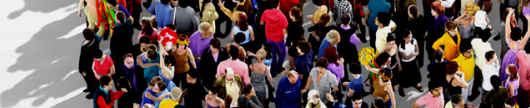

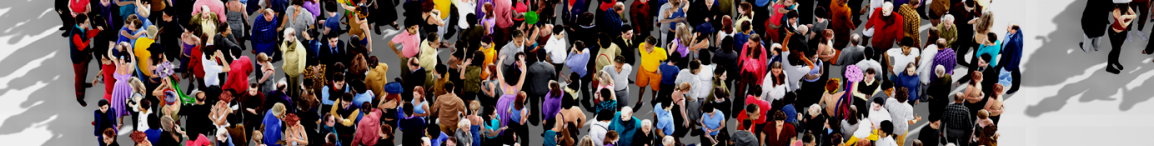

a. 1

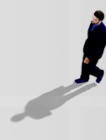

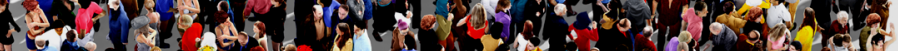

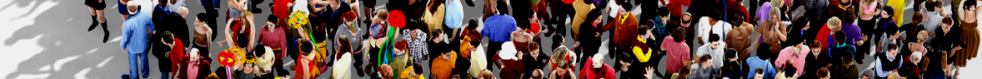

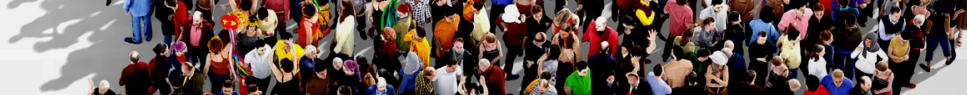
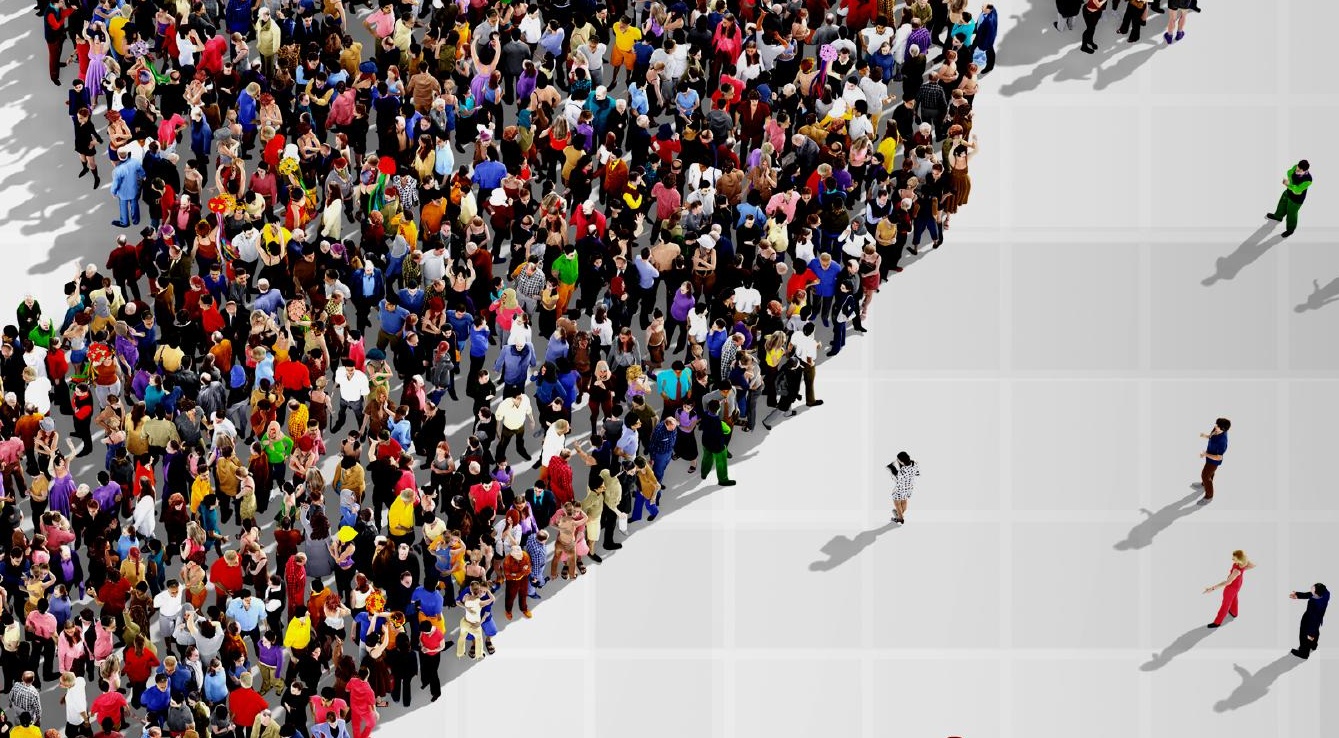

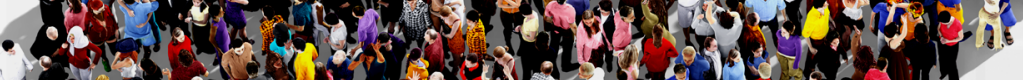

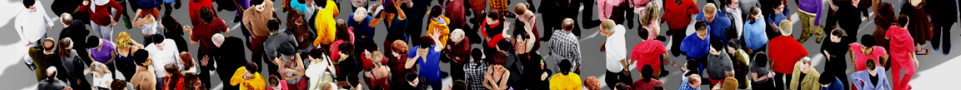

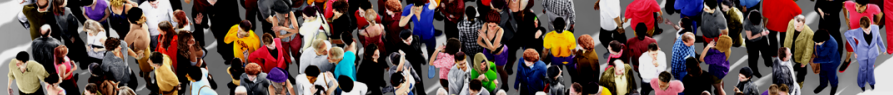

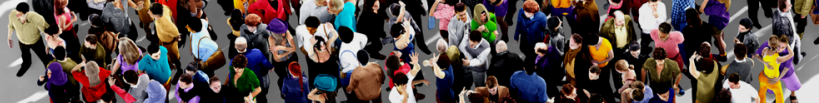

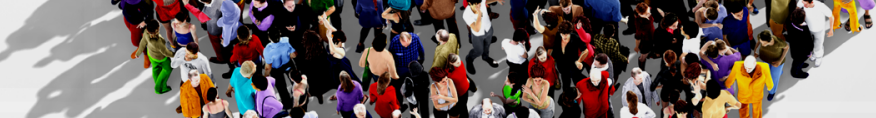

\title{
I.
}
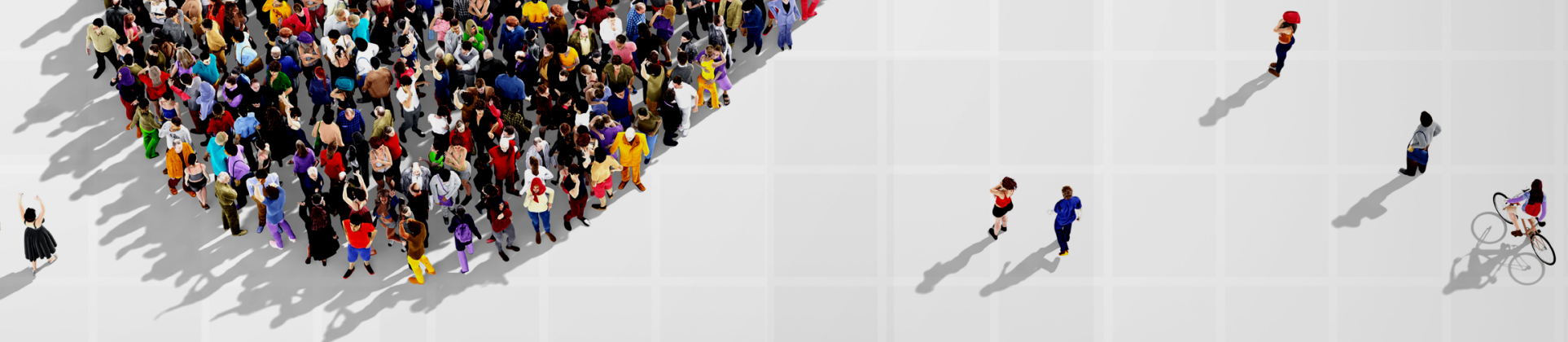


\section{PEGADA SOCIAL}

| POR RENATA PEREGRINO DE BRITO

\section{As cadeias de suprimento globais trazem como desafios assegurar o respeito aos Direitos Humanos e monitorar os impactos em todos os elos envolvidos.}

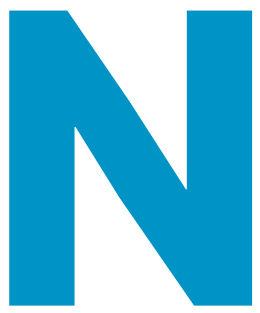

a mesa do chief supply-chain officer, o CSO, estão hoje decisões cujas consequências vão além dos muros da empresa. Com as cadeias de suprimento cada vez mais globais e interconectadas, a responsabilidade do CSO estende-se sobre as condições de trabalho e os impactos sociais e ambientais ao longo de todos os elos. Mesmo que não se tenha gestão direta de todos os processos, o que acontece na cadeia volta para a empresa e para o contratante.

Parece um paradoxo que a extensão da responsabilidade aconteça concomitantemente ao encurtamento da capacidade de gestão. Mas não deixa de ser razoável. As decisões sobre suprimentos envolvem (ou deveriam envolver) elementos que vão influenciar a competitividade da empresa $\mathrm{e}$ que trazem efeitos (positivos e negativos) para a sociedade. Entre esses elementos, destacam-se a análise de custos e a capacidade de monitoramento.

\section{QUANTO CUSTA?}

Um problema intrínseco das decisões de suprimentos está em terceirizar atividades produtivas com base na análise de custos. No cálculo de que comprar é mais barato que produzir, muitas vezes não se leva em conta como será o processo de produção dos contratados.

Acontece que as práticas das empresas terceirizadas, em alguns casos, vão a extremos, como o uso de trabalho forçado, trabalho infantil e demais violações de Direitos Humanos. Quando os fornecedores são flagrados realizando tais ações, a responsabilidade é também imputada às contratantes. Grandes marcas veem-se envolvidas em manchetes e relatos que não são nada lisonjeiros e tentam se defender, negando relação com o fato ou assumindo o compromisso de monitorar diferentemente a cadeia produtiva.

O caminho de negar a responsabilidade pode vir a ser juridicamente viável, mas é inócuo do ponto de vista de aprendizado. Já quando as empresas buscam se engajar, está implícito o entendimento de que o diálogo com os fornecedores e a busca de solução comum são preferíveis ao simples abandono da relação de fornecimento. Pode-se, até mesmo, trazer os concorrentes à mesa para promover a melhoria das práticas em cadeia de suprimentos comuns.

Contudo, os limites desse engajamento são apontados pelas próprias empresas quando não alteram as suas políticas 


\section{SALÁRIOS MÍNIMOS MENSAIS NOS PAÍSES EXPORTADORES DO SETOR DE VESTUÁRIO, EM US\$*}

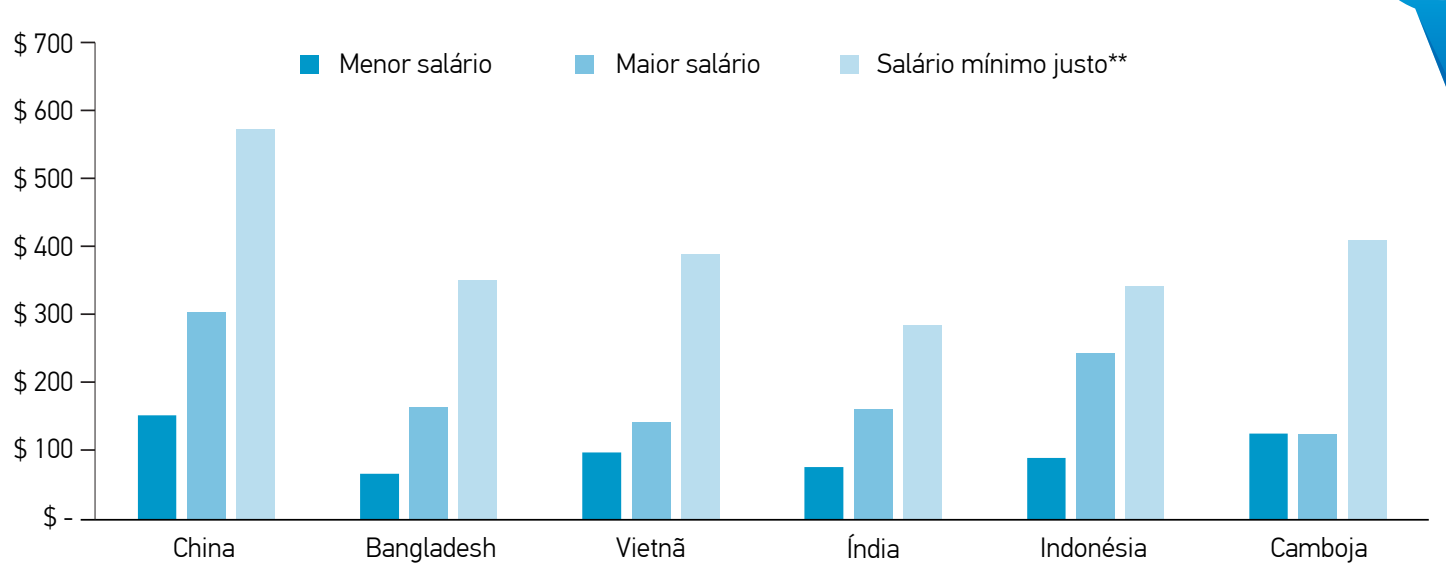

FONTE: ORGANIZAÇĀO INTERNACIONAL DO TRABALHO E ASIA FLOOR WAGE.

*VALORES EM US\$ COLETADOS EM JANEIRO DE 2015 E APLICÁVEIS A TRABALHADORES NÃO QUALIFICADOS; * *SALÁRIO MÍNIMO JUSTO CONSIDERA DESPESAS BÁSICAS DE ALIMENTAÇ̃̃O, MORADIA, EDUCAÇĀO E SAÚDE DE UMA FAMÍLIA.

de compras e de preços. Questões socioambientais passam a ser "mais um quesito" na negociação, desde que o preço permaneça o mesmo. Será mesmo possível essa equação?

Há empresas que afirmam ter encontrado soluções de menor impacto ambiental com redução de custos, via otimização no uso de recursos e ecoeficiência. Mas a mesma mágica é bem menos plausível em questões sociais e na relação com as pessoas, pois a contratação formal, a remuneração adequada e a pausa de trabalho custam mais caro. Segundo o site www.asia.floorwage.org, um salário mínimo justo nos principais países de produção de vestuário, como China e Bangladesh, requereria aumento de mais de $200 \%$ na remuneração atual (veja quadro). Portanto, o salário justo implica, no mínimo, duplicar gastos.

Os encargos não contabilizados pelas empresas, que os economistas chamam de externalidades, são os custos verdadeiros de produção (como mostra o documentário The True Cost, sobre os bastidores da indústria da moda). Contudo, as empresas não levam em conta esses custos na hora de contratar. Bangladesh é, aliás, um dos países que oferecem menores salários (US\$ 68/mês) e precárias condições de trabalho, sendo um dos principais exportadores de vestuário - o que dá indícios de quais são as reais prioridades das empresas do setor ao escolher seus fornecedores.

No projeto Better Work Programme, da Organização Internacional do Trabalho (OIT), que tem como objetivo melhorar o respeito aos direitos trabalhistas no setor de vestuário, os supervisores de fábricas, principalmente na Ásia, passam por um treinamento sobre como administrar pessoas, ter boas relações, comunicar-se, administrar o tempo e dividir o trabalho. Como resultado, as empresas participantes diminuíram os conflitos e tiveram aumento de $22 \%$ na produtividade. Contudo, o programa ainda não consegue chegar ao ponto de sugerir salários justos, pois não está claro se as empresas aceitarão o aumento de custos.

Voltando à análise de custo, a pergunta é: quanto custa fazer a coisa certa?

\section{COMO MONITORAR?}

Ao mesmo tempo em que cadeias de suprimento global vêm ajudando a diminuir custos de produção e a levar empregos para países em desenvolvimento, também vêm dificultando a capacidade de monitoramento e gestão de todas as empresas envolvidas. Seja pela distância física, seja pela cultural, a gestão internacional não é simples. Atinge as próprias operações offshore das organizações. Ou seja, dentro da mesma instituição o acompanhamento das práticas de gestão e dos Direitos Humanos às vezes se perde na distância.

Em cadeias globais, pode ser impraticável rastrear componentes de produtos como celulares e aparelhos eletrônicos e saber, por exemplo, se as encomendas estão contribuindo para o financiamento de grupos paramilitares. Em 2014, as empresas listadas na bolsa de valores dos Estados Unidos foram obrigadas a relatar se seus produtos continham minérios advindos da República Democrática do Congo e de países vizinhos. A exploração de minérios na região é uma das fontes de financiamento para grupos armados e responsável 


\title{
PRINCÍPIOS ORIENTADORES SOBRE EMPRESAS E DIREITOS HUMANOS DA ONU
}

\author{
CONSTITUÍDOS EM 2011, OS PRINCÍPIOS BASEIAM EM TRÊS PILARES:
}

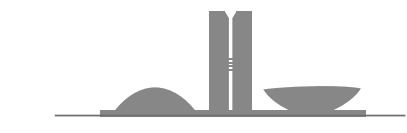

Estados têm a obrigação de proteger Direitos Humanos

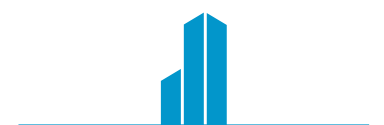

Empresas devem respeitar

Direitos Humanos

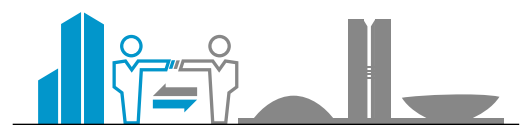

Estado e empresas devem prover meios para remediar os casos de descumprimento

Isso implica:

- Empresas devem ter compromisso formal com respeito aos Direitos Humanos e uma política de implementação desse compromisso;

- Empresas devem conhecer os seus impactos e, para tanto, auditar (due diligence) suas operações e suas cadeias;

- Empresas devem ser obrigadas a respeitar os Direitos Humanos mesmo em locais em que o governo ou empresas estatais não o façam.

Portanto:

O relaxamento de leis de auditoria não diminui a obrigação das empresas.

por graves violações de Direitos Humanos. Pela Lei DoddFrank 2010, seção 1.502, as empresas tiveram mais de três anos para promover transparência sobre suas cadeias de suprimentos, sem nenhuma sanção. Contudo, $80 \%$ das empresas admitiram que eram incapazes de determinar o país de origem dos minerais utilizados nos seus produtos. No estudo Challenges for Global Supply Chain Sustainability: Evidence from the Conflict Minerals Reports, os pesquisadores Yong Kim e Gerald Davis demonstraram que a grande complexidade das cadeias foi um dos maiores obstáculos para essa falta de controle. Mas, ao contrário do que poderia se pensar, empresas mais lucrativas e com iniciativas de responsabilidade social não se saíram melhor no processo de transparência.

\section{A SAIIDA ESTÁ NA TECNOLOGIA?}

Inovações tecnológicas, como blockchain (arquitetura de banco de dados compartilhada que deu origem ao bitcoin), prometem facilitar o monitoramento e promover transparência nas cadeias, uma vez que todos os envolvidos passam a ter acesso à base de dados, mesmo que a transparência esteja associada a pseudônimos.

Ao mesmo tempo, avanços tecnológicos como a inteligência artificial tendem a aumentar o contingente de desempregados e assim pressionar tais indivíduos para a aceitação de condições degradantes de trabalho. Segundo estudo da OIT, a busca de tecnologia e automação está exatamente nas áreas em que os custos de mão de obra têm aumentado. $\mathrm{O}$ avanço tecnológico não é uma bala de prata nem trará solução para os problemas da sociedade se não for direcionado para tanto.

O principal obstáculo para que as empresas deem um passo adiante parece não estar somente na capacidade de fazê-lo, mas na falta de compromisso. No setor de vestuário, flagrantes e tragédias não foram suficientes para que as empresas implementassem um compromisso de transparência na cadeia. Após o desabamento do prédio fabril Rana Plaza, em Bangladesh, em 2013, que matou 1.134 trabalhadores, foi criado um consórcio de empresas americanas importadoras de vestuário, Alliance for Bangladesh Worker Safety, para monitorar a segurança da indústria no país. Após três anos e meio, $50 \%$ dos problemas estruturais das fábricas ainda não estavam resolvidos.

É preciso recalibrar as prioridades da sociedade, e não se trata de frear a tecnologia, mas de direcionar esforços para cuidar dos legados negativos dos negócios. Esses esforços envolvem empresas, governo e sociedade e uma coalizão para o bem-estar social, como os Princípios Orientadores sobre Empresas e Direitos Humanos, promovidos pela Organização das Nações Unidas (ONU). Na complexidade do século 21, não há mais como dizer "isso não é problema meu" ou "é problema do governo". As soluções envolvem todos. Quando boas práticas deixarão de ser exceção e passarão a ser convencionais? Quando quisermos.

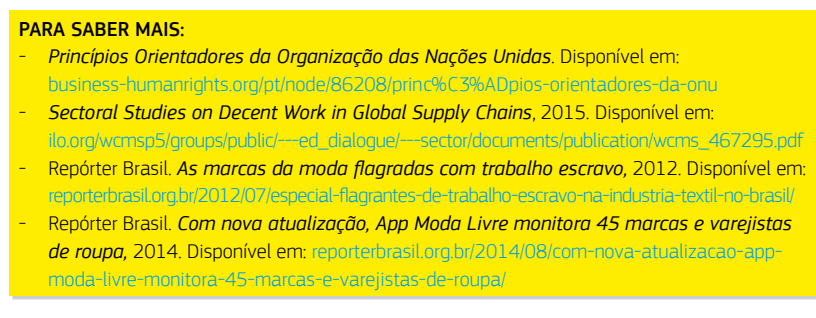

RENATA PEREGRINO DE BRITO > Pesquisadora convidada da Universidade de St. Gallen - Suíça > renata.brito@unisg.ch 